\title{
O potencial da concessão de florestas públicas para o desenvolvimento socioeconômico e geração de emprego na Amazônia Legal
}

\author{
Sergio Luiz do Bomfim \\ Serviço Florestal Brasileiro (SFB) \\ Alexandre Louis de Almeida D’Avignon \\ Ministério do Meio Ambiente (MMA) \\ Álvaro Nogueira de Souza \\ Universidade de Brasilia (UnB) \\ Paulo José Prudente de Fontes \\ Serviço Florestal Brasileiro (SFB) \\ Maísa Santos Joaquim \\ Universidade de Brasilia (UnB)
}

Na Amazônia Legal, diversas áreas com vocação para o manejo florestal sustentável padecem com baixos níveis de indicadores de qualidade de vida, contrastando com a riqueza de seus recursos naturais. O objetivo deste estudo foi identificar e analisar a concessão florestal como instrumento de política pública para promover melhorias socioeconômicas para aquela região. Para tanto, realizou-se um levantamento das glebas públicas aptas à concessão, por meio de dados pesquisados no Serviço Florestal Brasileiro. Então foi estimado o potencial de vagas, utilizando-se a proporção do volume de madeira produzida por emprego gerado. O prognóstico foi confrontado com a situação dos estados amazônicos no que se refere à desocupação, ocupação formal e pobreza extrema. Dos resultados gerados, verificou-se que a concessão de florestas públicas tem condições de contribuir para geração de emprego e renda e para o combate à pobreza na região.

Palavras-chave: política florestal, desenvolvimento socioeconômico, desenvolvimento sustentável, política de emprego, desigualdade social, pobreza

[Artigo recebido em 30 de janeiro de 2015. Aprovado em 22 de junho de 2016.] 


\section{El potencial de la concesión de los bosques públicos para el desarrollo socio- económico y la generación de empleo en la Amazonia}

En la Amazonia, varias áreas de aptitud para la gestión sostenible de los bosques sufren de bajos niveles de calidad de los indicadores de vida, en contraste con la riqueza de sus recursos naturales. El objetivo de este estudio fue identificar y analizar la concesión forestal como instrumento de política pública para promover mejoras socioeconómicas para la región. Para este propósito, hubo un estudio de las extensiones adecuadas para la concesión, por medio del Servicio Forestal Brasileño. Luego se estimó los puestos de trabajo que se pueden crear, utilizando la proporción del volumen de madera producida por empleo generado. El pronóstico fue confrontado con la situación de los estados amazónicos en relación al desempleo, la ocupación formal y la pobreza extrema. Los resultados generados permitieron verificar que la concesión de los bosques públicos es capaz de contribuir a la generación de empleo e ingresos y a la lucha contra pobreza en la región.

Palabras clave: política forestal, desarrollo socioeconómico, desarrollo sostenible, política de empleo, desigualdad social, pobreza

The Potential of the public forests concession for the socioeconomic development and generation of employment in the Legal Amazon

In the Amazon, several areas calling for sustainable forest management suffer with low levels of quality of life indicators, in contrast to the exuberance of its natural resources. The aim of this study was to identify and analyze forest concessions as a public policy instrument to promote socioeconomic improvements in the region. For this purpose, initially, there was a survey of public plots suitable for the grant through data surveyed in the Brazilian Forest Service. So, it estimated the potential vacancies using the ratio of the volume of wood produced by employment generated. The prognosis was faced with the situation of the Amazonian states in regard to unemployment, formal occupation and extreme poverty. Regarding the generated results, it was found that the concession of public forests is able to contribute to the generation of employment and income and combating poverty in the region.

Keywords: forest policy, socioeconomic development, sustainable development, employment policy, social inequality, poverty 


\section{Introdução}

A partir dos anos 1970, segundo Simon e Garagorry (2005), intensificou-se na Amazônia um processo de ocupação baseado no antigo modelo que ocorreu no sul do Brasil, sendo, aliás, grande parte de seus desbravadores proveniente dos estados do sul e do sudeste do País.

No entendimento de Bomfim (2014), as florestas naturais, na maioria das vezes, são percebidas como entraves para aqueles que culturalmente veem, na atividade agropecuária, a única opção para o uso do solo. À vista disso, a potencialidade econômica dos bens florestais nativos e serviços ambientais pertinentes são desconhecidos ou considerados irrelevantes. Tal fato, concordando com Wunder et al. (2008), ajuda a explicar o porquê dos preços das terras ocupadas com florestas nativas na Amazônia, em geral, serem menores do que aqueles referentes às áreas desmatadas com características semelhantes.

O que se pode deduzir é que o desconhecimento dos valores dos ativos florestais, por não implicar em um possível abatimento no custo de "limpeza" da terra, majora os preços das propriedades desflorestadas e reduz o valor da floresta. Pelo mesmo motivo, o manejo florestal sustentável é comumente visto como empreendimento marginal, enfrentando, conforme apontado por Bomfim (2014), problemas para competir com as demais formas de uso alternativo do solo.

Também na concepção de Bomfim (2014), o capital constituído pelas florestas naturais vem, gradativamente, perdendo importância relativa como fonte de renda e sobrevivência para comunidades situadas em suas proximidades. De acordo com o autor, na região, é comum a existência de localidades que contrastam um grande potencial de geração de riqueza, mediante a utilização racional de suas florestas, com a baixa qualidade de vida de seus habitantes.

Informações geradas por Serviço Florestal Brasileiro (SFB) e Instituto do Homem e Meio Ambiente da Amazônia (Imazon) (2010) e por Pereira et al. (2010) permitiram identificar o setor florestal como importante segmento da economia na geração de renda e riqueza para a região. Porém, a informalidade, carência de instrumentos econômicos de indução, assimetria de informação e insuficiência de ordenamento das atividades no setor comprometem a consolidação do empreendedorismo florestal como um dos pilares da economia regional.

Kramer, Holmes e Haefele (2003), desde o início dos anos 2000, já argumentavam que, melhorando a compreensão da importância econômica da estrutura, saúde e extensão dos ecossistemas florestais, as decisões de gestão e política florestal poderiam ser mais racionais, reduzindo falhas de mercado e de governo. 
Segundo Kahn (2008), muitos seriam os critérios aplicáveis às políticas públicas e à tomada de decisão referente aos possíveis usos dos recursos naturais. Exemplos desses critérios são a equidade, sustentabilidade, integridade ecológica, justiça ambiental, participação do público e eficiência econômica.

Heidemann e Salm (2010), por sua vez, consideraram, genericamente, a política pública como o conjunto de decisões e ações de governo. Para esses pesquisadores, em termos político-administrativos, o desenvolvimento de uma sociedade é função do exercício dos governos dos estados nacionais, subnacionais e supranacionais em consonância com as demais forças da sociedade, sobretudo as forças de mercado em seu sentido lato.

Na esfera florestal, Rocha e Silva (2009) avaliaram que, visando à harmonia entre as ações político-institucionais do Estado e os interesses da sociedade, é necessário que as políticas públicas para o setor sejam alicerçadas em funções como macroplanejamento, administração, extensão, fomento, pesquisa, monitoramento e fiscalização dos recursos florestais.

Albuquerque (2009), sob outra perspectiva, ponderou a concessão florestal como indutora de importantes avanços, citando a inclusão de aspectos ambientais, sociais, culturais e econômicos aos princípios legais e também a intensificação da participação social e a promoção de um novo conceito de floresta pública.

Já na visão de Campos (2011), as principais finalidades da concessão florestal são as de satisfazer a demanda por madeira, contribuir no mecanismo de desenvolvimento do setor madeireiro, promover a melhoria social com geração de empregos, incentivar o uso de técnicas de colheita florestal mitigadoras de danos ambientais e auxiliar no combate ao desmatamento.

Consoante o SFB (2016a), a concessão de florestas públicas foi estabelecida, em 2006 , com o objetivo principal de conservar as florestas brasileiras, considerando a melhoria da qualidade de vida da população que vive em seu entorno e o estímulo à economia formal, no que tange aos produtos e serviços oriundos de florestas nativas. Dessa forma, tornou-se possível o manejo de florestas públicas por parte de empresas privadas e comunidades tradicionais para obtenção de produtos madeireiros e não madeireiros e para a execução de ecoturismo.

Ocorre que, para o ano de 2011, conforme o Instituto de Pesquisa Econômica Aplicada (Ipea) (2016), o SFB projetou uma produção de $2.881 .061 \mathrm{~m}^{3}$ de madeira proveniente de concessão. No entanto, o Relatório de Gestão de 2011 do SFB (2016b) informa que a produção de madeira dos concessionários naquele ano foi de $19.156,78 \mathrm{~m}^{3}$, ou seja, menos de $1 \%$ do esperado. Mesmo considerando um desempenho atualizado, a produção representa cerca de 4,3\% da projeção realizada para 2011, conforme o Relatório de 2015 do SFB (2016b). Com efeito, 
concordando com Góis (2011), é perceptível que os resultados esperados quando da promulgação da Lei no 11.284/2006 (Lei de Gestão de Florestas Públicas), pelo menos em termos de ganhos econômicos, sociais e ambientais, ainda não foram efetivamente alcançados.

Obviamente, seguindo a mesma magnitude, indicadores como arrecadação, geração de empregos e investimentos em projetos sociais também estiveram abaixo das previsões. Ademais, ainda não há registros de manejo de produtos não madeireiros e serviços de turismo idealizados pelo governo, como pode ser verificado nos relatórios de gestão do SFB (2016b). Todavia, não é intenção deste trabalho versar sobre os obstáculos que impediram o alcance dessas metas.

O presente estudo tem como objetivo principal identificar e analisar o potencial da concessão florestal em proceder melhorias socioeconômicas e gerar emprego e renda para a Amazônia. Em segundo plano, visa chamar atenção para esse modelo de outorga e recrudescer o debate sobre sua potencialidade em se tornar um instrumento político capaz de elevar a qualidade de vida da população amazônica, mediante um modelo sustentável de uso das florestas públicas.

\section{Material}

\section{Área de estudo}

A Amazônia Legal é o locus deste trabalho. A Lei no 12.651, de 25 de maio de 2012 (BRASIL, 2012), estabeleceu que a região é formada pelos Estados do Acre, Pará, Amazonas, Roraima, Rondônia, Amapá e Mato Grosso e pelas regiões situadas ao norte do paralelo $13^{\circ} \mathrm{S}$ dos Estados de Tocantins e Goiás e ao oeste do meridiano de $44^{\circ} \mathrm{W}$ do Estado do Maranhão.

Como levantado por Bomfim (2014), a região abriga o total de florestas públicas naturais atualmente aptas à prática do regime de manejo sustentável por meio de concessão florestal (60,4 milhões de ha), considerando os aspectos fundiários, legais, técnicos e socioeconômicos necessários.

\section{Levantamento de dados}

Em face do universo de dados necessários para o estudo, seguindo Bomfim (2014), o levantamento foi realizado por meio de fontes secundárias, pesquisas de campo realizadas e cedidas pelo Serviço Florestal Brasileiro (SFB) e também mediante informações contidas em documentos publicados pelos órgãos florestais estaduais, além de literatura disponível na internet. 
Assim, foram empregados:

a. dados do SFB e dos serviços florestais estaduais (período de 2010 a 2013), a saber, áreas passíveis de uso para concessões florestais, produtividade de madeira e ciclo de corte para o manejo florestal sustentável;

b. dados de revisão de literatura, de pesquisa em endereços eletrônicos e de empresas concessionárias sobre geração de emprego e renda;

c. dados de revisão de literatura e pesquisa em endereços eletrônicos das instituições responsáveis pelos temas socioeconômicos e produção florestal, isto é, população economicamente ativa, número de carteiras assinadas, desocupação, pobreza extrema e produção de produtos florestais madeireiros e não madeireiros (IBGE, Ipea e Dieese, no período de 2001 a 2014).

\section{Método}

A existência de localidades ricas em florestas públicas na Amazônia, porém pouco desenvolvidas socioeconomicamente, como abordado por Bomfim (2014), suscitou a relevância de se identificar e analisar o potencial da concessão florestal como instrumento econômico da política nacional do meio ambiente para contribuir na transformação dessa realidade.

Para esse fim, estimaram-se as quantidades potenciais de empregos e de renda passíveis de serem geradas pela concessão de florestas públicas na Região Amazônica. A partir dessa potencialidade e de forma condizente com os procedimentos metodológicos adotados por Bomfim (2014), foi avaliada a magnitude dos virtuais impactos sobre aspectos socioeconômicos, quais sejam, população economicamente ativa (PEA), emprego formal com carteira assinada, desocupação e pobreza extrema (PE).

O manejo sustentável realizado em florestas públicas por meio de concessão, por excelência e obrigatoriedade legal, deve obedecer a técnicas de baixo impacto ambiental, como apresentado por Bomfim (2014). Essa atividade tem visível capacidade de criação de empregos formais, verdes e sustentáveis, quando comparada às demais formas de uso alternativo do solo (agricultura, pecuária e mineração, entre outras).

A geração de emprego formal ocorre em função das regras das concessões florestais e em obediência às leis trabalhistas, impondo que todos os trabalhadores das concessionárias sejam devidamente registrados, como tratado por SFB (2013c).

Empregos verdes, na concepção das Nações Unidas, conforme Allen e Clouth (2012), consistem no trabalho em agricultura, manufatura, pesquisa e desenvolvimento e administração que contribui substancialmente para proteger 
os ecossistemas e a biodiversidade, reduzir o uso de energia e de materiais, racionalizar o consumo de água, descarbonizar a economia e minimizar ou evitar geração de todas as formas de desperdício e poluição. Tais atividades se enquadram nas relacionadas à concessão florestal.

Por fim, a qualidade de um emprego ser sustentável deve-se à exigência legal (Lei no 11.284/2006) de utilização da floresta em ciclos contínuos e de realização da colheita em frações de áreas ajustadas aos ciclos de corte e em períodos anuais. Essas exigências levam ao uso uniforme e perpétuo dos recursos florestais, como pode ser verificado em Brasil (2006).

A criação de cada emprego, por sua vez, invoca um esperado efeito positivo no combate à $\mathrm{PE}$, a qual ainda possui presença marcante nos estados amazônicos, conforme Bomfim (2014).

O Instituto de Pesquisa Econômica Aplicada (Ipea) (2014) conceitua a PE como o número de pessoas em domicílios com renda domiciliar per capita inferior ao valor de uma cesta de alimentos com o mínimo de calorias necessárias para suprir adequadamente uma pessoa. Esse conceito, ainda de acordo com Ipea (2014), baseia-se em recomendações da Food and Agriculture Organization (FAO) e da Organização Mundial da Saúde (OMS).

\section{Concessão florestal e uso alternativo do solo}

A adoção da concessão florestal como instrumento de política pública pode estabelecer, no mínimo, duas situações vantajosas para o empreendedor quando se compara ao manejo em áreas privadas: regularidade fundiária e status de certificação.

Conforme Especial Revista Veja (2009), as áreas com títulos de propriedade na região somavam, em 2009, apenas $4 \%$ de sua superfície total, o que corrobora a constatação de Sabogal et al. (2006) sobre a crítica realidade fundiária regional. Ainda de acordo com Especial Revista Veja (2009), as pessoas tendem a buscar o benefício imediato, em detrimento de investimentos de longo prazo, quando não há segurança legal e jurídica em dado ambiente.

Arima e Barreto (2002) avaliaram que o custo da madeira produzida em terras privadas na região de Tapajós ficava maior em cerca de $25 \%$ em relação ao custo em terras públicas. Mesmo após mais de uma década desse estudo, considerando o baixo ritmo do mercado de madeira nativa, é sensato considerar que a diferença constatada por Arima e Barreto (2002) permaneça. Segundo o Instituto Internacional de Educação do Brasil (IEB) (2011), boa parte dessa diferença pode ser atribuída à questão fundiária. 
No que concerne à certificação, as exigências e o monitoramento afetos aos contratos de concessão florestal possuem considerável convergência a esse processo de acreditação comercial. Em concordância com Bomfim (2014), é certo que ainda não se tem estabelecido um mercado devidamente atrativo para despertar de forma consistente o interesse para a adoção de um sistema tão complexo e oneroso. Porém, por ser algo novo para o setor, é de se esperar que quem saia na frente consiga uma importante vantagem comercial.

Para Oliveira (2013), a concessão florestal despontou como um instrumento racional de gestão de um recurso natural com forte apelo estratégico. Sua eficiência e eficácia passam pela capacidade de reorganização governamental, a fim de poder proporcionar frutos econômicos e socioambientais a partir do uso sustentável de um patrimônio público em benefício de todos.

Como exposto por Sauer e Leite (2012), o início dos anos 2000 foi marcado por uma notável valorização fundiária, incluindo a Amazônia, decorrente do aquecimento do mercado das commodities agrícolas. Paralelamente, e em função desse aquecimento, cresceram também as ofertas de atraentes linhas de financiamento, o que obviamente pressionou ainda mais os preços das terras agricultáveis.

Entretanto, segundo Bomfim (2014), ao mesmo tempo em que as commodities agrícolas se tornavam mais atrativas e os incentivos para sua expansão se mostravam generosos, ampliava-se a insegurança para quaisquer empreendimentos que envolvessem o manejo sustentável da floresta ou mesmo para a sua conversão legal para o uso alternativo do solo.

Conforme apontado por Bomfim (2014), na década de 2000, seguindo a lógica de valoração semelhante aos preços das terras (como era de se esperar pelo conceito de custo de oportunidade), alguns dos principais produtos florestais da Amazônia perderam força como agentes geradores de renda para a população local. Tal fato, demonstrado nos resultados deste trabalho, indica uma fragilização do aproveitamento comercial das florestas nativas em comparação às tradicionais formas de uso alternativo do solo.

Isso posto, a concessão florestal surge como um propenso instrumento de política pública capaz de disciplinar e fomentar o manejo sustentável em florestas estatais, podendo coadunar a manutenção da floresta com sua efetiva participação no desenvolvimento socioeconômico regional.

\section{Áreas de concessão}

As áreas passíveis de concessão foram estimadas com base em dados fornecidos por SFB (2010, 2013a, 2013b). Foram, então, consultados os planos anuais de outorga florestal (Paof) e o Cadastro Nacional de Florestas Públicas. 
Acompanhando Bomfim (2014), foram considerados $60 \%$ do montante da superfície de florestas nacionais, florestas estaduais e florestas públicas não destinadas, federais e estaduais, para estimar a área total de concessão (ATC). Ainda com base em Bomfim (2014), a área de efetivo manejo (AEM) corresponde a 75\% da ATC foi estipulada em concordância com os editais de licitação do SFB (2012, 2013c). Para tanto, levou-se em conta a exclusão de áreas de preservação permanente (estimadas em $20 \%$ da ATC) e de reserva absoluta (igual a $5 \%$ da ATC, conforme a Lei $\mathrm{n}$ ㅇ 11.284/2006).

$\mathrm{AEM}=\mathrm{ATC} \times 0,75$

Em que:

AEM - área de efetivo manejo;

ATC - área total para concessão.

\section{Empregos}

Para avaliar o número total de empregos susceptíveis de formação por intermédio da concessão florestal, foram definidas relações entre o volume de toras extraídas (metros cúbicos) e os empregos diretos e indiretos gerados pelo setor. Os cálculos foram efetuados a partir de dados de Pereira et al. (2010).

Logo, em concordância com Bomfim (2014), para a relação de empregos diretos gerados na floresta, foi dividido o total de toras produzido no ano de 2009 na Amazônia (14,148 milhões de metros cúbicos) pelo total de empregos (21.963) das atividades de campo (corte, traçamento, arraste, baldeio, movimentação de pátios e transporte). O mesmo procedimento foi feito para empregos diretos gerados na indústria madeireira (14,148 milhões de metros cúbicos $\div 44.676$ empregos).

A relação entre área manejada e geração de empregos foi estipulada por meio da produtividade de 0,86 m³/ha/ano, constante na Resolução Conama no 306, de 06 de fevereiro de 2009.

Área (ha) $/$ emprego $=\left(\mathrm{m}^{3}\right.$ tora/emprego $) \div 0,86$

Os empregos a serem gerados pela concessão (EGC) foram calculados, continuando com Bomfim (2014), pela divisão entre as áreas de efetivo manejo, estimadas para cada estado, e o valor da relação área (ha)/emprego.

$E G C=A E M \div R A E$

Em que:

EGC - empregos a serem gerados pela concessão;

AEM - área de efetivo manejo;

$\mathrm{RAE}$ - relação área/emprego. 
Na Tabela 1, são apresentados os resultados das relações de empregos diretos e indiretos na floresta e na indústria madeireira por volume de tora extraída $\left(\mathrm{m}^{3}\right)$ e área manejada (ha). A proporção de 2,06 empregos indiretos para cada emprego direto foi baseada nos estudos de Pereira et al. (2010).

\begin{tabular}{lll}
\hline Item & $\mathrm{m}^{3}$ & ha \\
\hline Relação volume e área/emprego direto na floresta & 644,17 & 749,03 \\
$\begin{array}{l}\text { Relação volume e área/emprego direto na indústria } \\
\text { madeireira }\end{array}$ & 316,68 & 368,23 \\
Relação volume e área/emprego indireto & 103,22 & 120,02 \\
Relação volume e área/emprego direto + indireto & 69,45 & 80,76 \\
\hline
\end{tabular}

Fonte: Elaboração própria, a partir de Pereira et al. (2010).

\section{Massa salarial e valor de referência da pobreza extrema}

Levando-se em conta, então, o número factível de empregos a serem gerados pela concessão florestal (CF), foi possível calcular o montante de renda líquida referente às potenciais vagas, o valor de referência (VR) da PE (total de pessoas em PE multiplicado pelo valor da cesta básica) e a relação percentual entre a massa da renda passível de ser gerada pela CF e o VR da PE, para cada estado da Amazônia Legal.

Os cálculos obedeceram às seguintes premissas:

a. valor da cesta básica em Manaus/AM de R\$̦ 258,32 (DEPARTAMENTo INTERSINDICAL DE ESTATístICA E ESTUdos SOCIOECONÔMICOS, 2014a), que era em novembro 2011 o mais alto da região;

b. valor do salário mínimo em 2011 , de $R \$ 545,00$ bruto e $R \$ 501,40$ líquido (DEPARTAMENTo INTERSINDICAL de Estatística E Estudos Socioeconômicos, 2014b), para inferir o poder de compra de cestas básicas e

c. todos os empregos remunerados com base no salário mínimo.

\section{Resultados e discussão}

\section{Valor da terra e valor per capita dos principais produtos florestais}

Concordando com Bomfim (2014), infere-se que a pressão exercida pelas commodities aliada: i) à confusa estrutura fundiária; ii) aos engessados arcabouços legal e burocrático de licenciamento ambiental; e iii) ao obscuro mercado de bens florestais, acabaram por gerar considerável distorção entre os preços de imóveis com e sem cobertura de matas na Amazônia.

Para asseverar a conclusão anteriormente exposta, que se coaduna com os levantamentos de Wunder et al. (2008) e Reydon (2011), foram realizadas, para o 
presente estudo, consultas em sítios eletrônicos de organizações que trabalham com o mercado de terras rurais. As pesquisas demonstraram que, em média, fazendas com pastagem na região amazônica são ofertadas na ordem de $\mathrm{R} \$ 2.600,00 /$ ha. Em contrapartida, as propriedades revestidas com florestas naturais são oferecidas em torno de apenas $\mathrm{R} \$ 390,00 /$ ha, ou seja, áreas com florestas são avaliadas com preços cerca de $85 \%$ menores em relação àquelas que já foram desmatadas.

Já em relação aos bens oriundos de florestas naturais, analisando os dados do Instituto Brasileiro de Geografia e Estatística (IBGE) (2013a) relativos aos anos de 2001 a 2009, apurou-se que os valores de produção de dez dos principais produtos florestais nativos, calculados per capita e corrigidos pelo Índice Nacional de Preços ao Consumidor Amplo (IPCA) (ano base 2009), reduziram ou ficaram estagnados (Figura 1). As exceções foram o óleo de copaíba e a amêndoa de cumaru, que, no entanto, são os menos representativos em termos de geração de renda.

Figura 1 - Valor da produção per capita dos principais produtos florestais da Amazônia

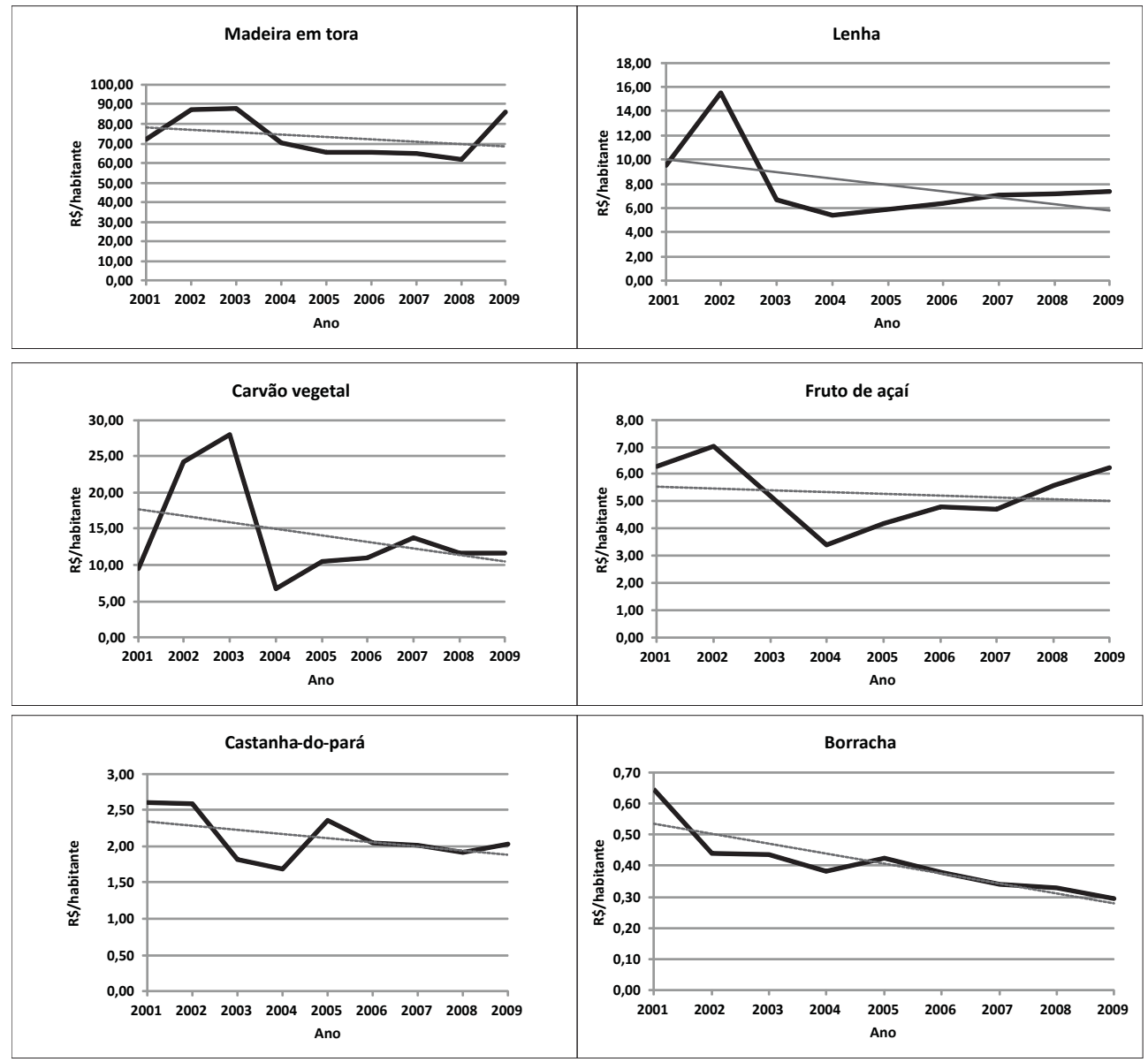




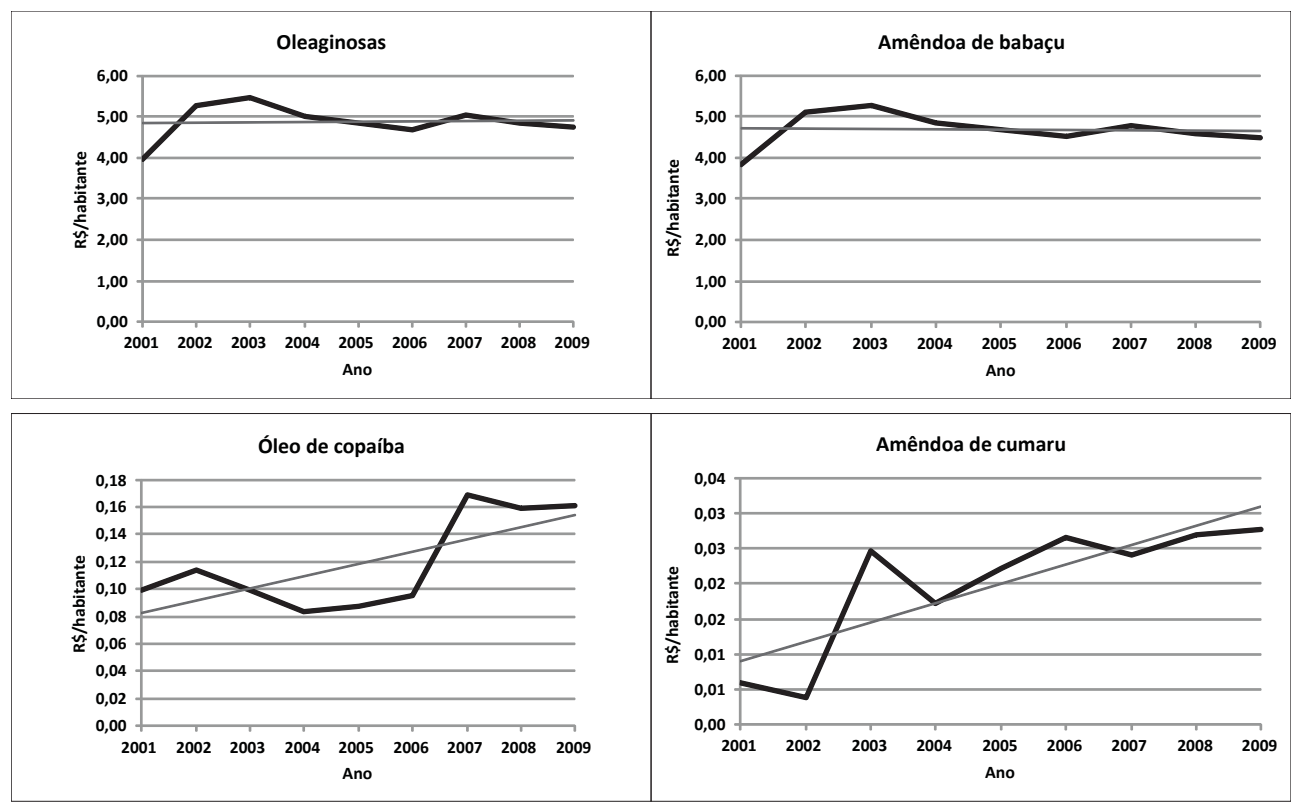

Fonte: Elaboração própria, a partir de IBGE (2013a).

\section{Projeção de empregos pela concessão}

Utilizando-se as relações constantes na Tabela 1, foi calculada a estimativa de empregos diretos e indiretos passíveis de serem gerados na hipótese de ocupação plena das florestas públicas propensas à concessão, conforme apresentada na Tabela 2.

Tabela 2 - Áreas totais e potenciais e estimativa de geração de empregos mediante concessão florestal na Amazônia Legal

\begin{tabular}{lllllll}
\hline & \multicolumn{2}{l}{$\begin{array}{l}\text { Florestas públicas cadastradas } \\
\text { (mil ha) }\end{array}$} & \multicolumn{2}{c}{ Empregos estimados (mil) } \\
\cline { 2 - 7 } Estado & Total & $\begin{array}{l}\text { Potencial } \\
\text { para } \\
\text { concessão }\end{array}$ & $\begin{array}{l}\text { Efetivo } \\
\text { manejo }\end{array}$ & Diretos & Indiretos & Total \\
\hline Acre & $8.937,51$ & 727,63 & 545,72 & 2.211 & 4.547 & 6.758 \\
Amapá & $9.042,27$ & $1.954,03$ & $1.465,52$ & 5.936 & 12.211 & 18.147 \\
Amazonas & $129.148,48$ & $34.462,82$ & $25.847,12$ & 104.699 & 215.357 & 320.056 \\
Maranhão & $4.485,54$ & 212,01 & 159,00 & 644 & 1.325 & 1.969 \\
Mato & $17.971,62$ & 651,33 & 488,50 & 1.979 & 4.070 & 6.049 \\
Grosso & $75.155,21$ & $18.008,75$ & $13.506,57$ & 54.711 & 112.536 & 167.247 \\
\hline Pará & & & & & & \\
\hline
\end{tabular}




\begin{tabular}{lllllll}
\hline \multirow{2}{*}{ Estado } & \multicolumn{3}{l}{$\begin{array}{l}\text { Florestas públicas cadastradas } \\
\text { (mil ha) }\end{array}$} & \multicolumn{5}{c}{ Empregos estimados (mil) } \\
\cline { 2 - 7 } & Total & $\begin{array}{l}\text { Potencial } \\
\text { para } \\
\text { concessão }\end{array}$ & $\begin{array}{l}\text { Efetivo } \\
\text { manejo }\end{array}$ & Diretos & Indiretos & Total \\
\hline Rondônia & $16.360,50$ & $2.580,62$ & $1.935,47$ & 7.840 & 16.126 & 23.966 \\
Roraima & $16.913,03$ & $1.757,06$ & $1.317,80$ & 5.338 & 10.980 & 16.318 \\
Tocantins & $4.228,70$ & 21,10 & 15,83 & 64 & 132 & 196 \\
\hline Total & $282.242,86$ & $60.375,35$ & $45.281,53$ & 183.422 & 377.284 & 560.706 \\
\hline
\end{tabular}

Fontes: Elaboração própria, a partir de SFB (2012); SFB (2013b).

\section{Efeito esperado na mitigação da PE}

O efeito favorável da concessão florestal na mitigação da PE foi projetado de forma cautelosa. Além de ter sido considerada a massa salarial apenas pelo piso (salário mínimo), não foram reputados benefícios econômicos como, por exemplo, o reflexo do aumento de arrecadação tributária proporcionado pelas concessões florestais e investimentos diretos dos concessionários em projetos sociais. Também não foram incluídos nas previsões produtos não madeireiros e serviços como o ecoturismo. Logo, foi considerada apenas a atividade madeireira como geradora de renda.

Para a área estimada de 45,3 milhões de hectares de efetivo manejo via concessões de florestas públicas, a previsão é de criação de 560.706 empregos (diretos e indiretos). O montante da renda potencial dos salários dos empregos, assim gerados, representa cerca de $36,3 \%$ do valor relacionado ao flagelo da PE na Amazônia Legal (Tabela 3).

Tabela 3 - Empregos potenciais da CF, renda líquida estimada, pessoas que vivem em PE, VR da PE e relação renda salarial esperada $x$ VR da PE, por estado da Amazônia Legal (2011)

\begin{tabular}{lccccc}
\hline Estado & $\begin{array}{c}\text { Empregos } \\
\text { poten- } \\
\text { ciais (n-) }\end{array}$ & $\begin{array}{c}\text { Renda líquida } \\
\text { dos empregos } \\
\text { potenciais (R\$/ } \\
\text { mês) }\end{array}$ & $\begin{array}{c}\text { Pessoas } \\
\text { em PE (n-) }\end{array}$ & $\begin{array}{c}\text { VR da PE (R\$̦/ } \\
\text { mês) }\end{array}$ & $\begin{array}{c}\text { Relação } \\
\text { renda } \\
\text { salarial } \\
\text { x VR da } \\
\text { PE (\%) }\end{array}$ \\
\hline Acre & 6.758 & $3.388 .461,20$ & 78.566 & $20.295 .169,12$ & 16,7 \\
Amapá & 18.147 & $9.098 .905,80$ & 61.342 & $15.845 .865,44$ & 57,4 \\
\hline
\end{tabular}




\begin{tabular}{|c|c|c|c|c|c|}
\hline Estado & $\begin{array}{l}\text { Empregos } \\
\text { poten- } \\
\text { ciais ( } \mathrm{n}-\mathbf{)}\end{array}$ & $\begin{array}{c}\text { Renda líquida } \\
\text { dos empregos } \\
\text { potenciais (R\$/ } \\
\text { mês) }\end{array}$ & $\begin{array}{l}\text { Pessoas } \\
\text { em PE ( } n \text { o) }\end{array}$ & $\begin{array}{c}\text { VR da PE (R\$/ } \\
\text { mês) }\end{array}$ & $\begin{array}{c}\text { Relação } \\
\text { renda } \\
\text { salarial } \\
\text { x VR da } \\
\text { PE (\%) }\end{array}$ \\
\hline Amazonas & 320.056 & $160.476 .078,40$ & 397.000 & $102.553 .040,00$ & 156,5 \\
\hline Maranhão & 1.969 & $987.256,60$ & 1.254 .832 & $324.148 .202,24$ & 0,3 \\
\hline $\begin{array}{l}\text { Mato } \\
\text { Grosso }\end{array}$ & 6.049 & $3.032 .968,60$ & 53.013 & $13.694 .318,16$ & 22,1 \\
\hline Pará & 167.247 & $83.857 .645,80$ & 915.008 & $236.364 .866,56$ & 35,5 \\
\hline Rondônia & 23.966 & $12.016 .552,40$ & 95.632 & $24.703 .658,24$ & 48,6 \\
\hline Roraima & 16.318 & $8.181 .845,20$ & 25.425 & $6.567 .786,00$ & 124,6 \\
\hline Tocantins & 196 & $98.274,40$ & 113.692 & $29.368 .917,44$ & 0,3 \\
\hline Total & 560.706 & $281.137 .988,40$ & 2.994 .510 & $773.541 .823,20$ & 36,3 \\
\hline
\end{tabular}

Fonte: Elaboração própria, a partir de Instituo de Pesquisa Econômica Aplicada (2014).

A possibilidade de aumento de renda pelas famílias, mediante os empregos criados, oferece à concessão florestal um olhar objetivo tanto pelos gestores públicos como pela sociedade. Essa ferramenta de manejo sustentável dos recursos florestais, conforme se pode verificar analisando a Tabela 3, apresenta potencial para proporcionar um expressivo ganho social para a região. Isso inclui, consoante observação de Bomfim (2014), a perspectiva de resgate de relevante parcela de seus moradores que vive em condições de PE.

Individualmente, vale destacar os Estados do Amazonas e de Roraima, nos quais a concessão florestal tem capacidade de gerar renda acima do VR da PE. Isso permite presumir que os benefícios sociais esperados podem, virtualmente, ultrapassar os limites territoriais dos citados estados, mediante, por exemplo, a importação de mão de obra.

\section{Efeitos sobre PEA, carteiras assinadas e desocupação}

A estimativa de criação de empregos na Amazônia via concessão florestal corresponde a $4,39 \%$ da PEA da região. A maior relação foi $19,26 \%$, referente ao Estado do Amazonas (Figura 2).

A PEA inclui todos os indivíduos com 10 anos ou mais de idade que estavam procurando ocupação ou trabalhando na semana de referência da Pesquisa Nacional por Amostra de Domicílios (Pnad/IBGE), de acordo com o Ipea (2013a). 
Figura 2 - Percentual da quantidade potencial de geração de empregos diretos e indiretos pela CF em relação à PEA, por estado da Amazônia

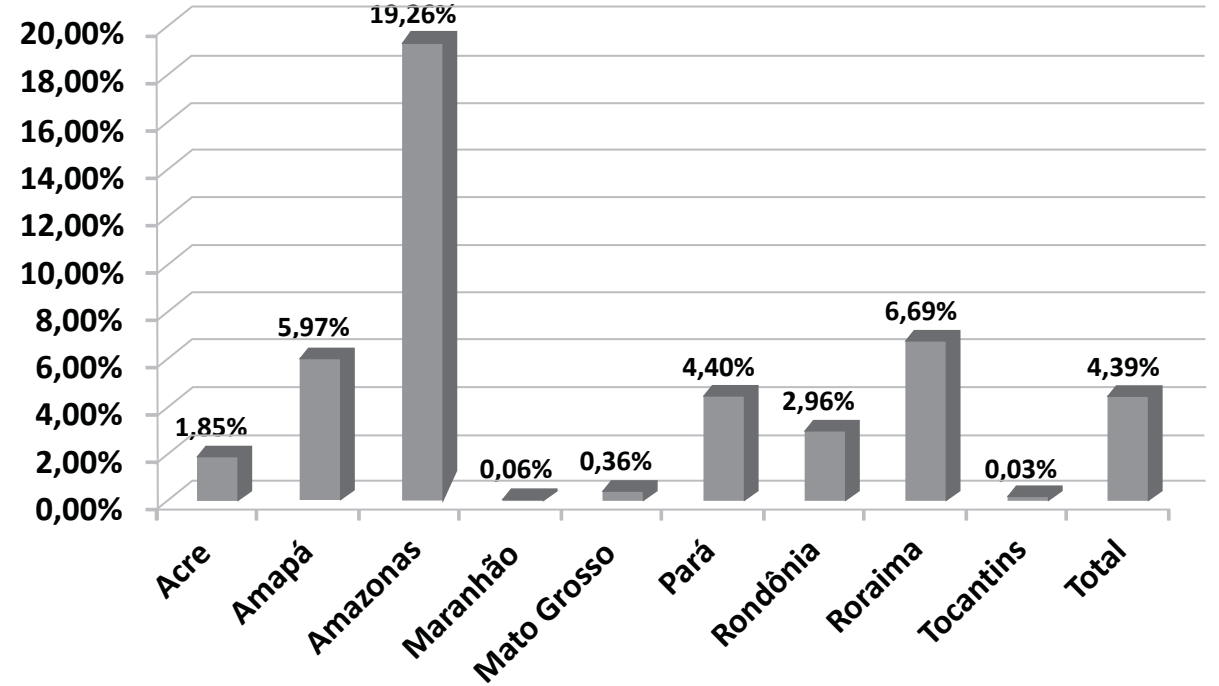

Fontes: Elaboração própria, a partir de IBGE (2014).

No que concerne à quantidade de trabalhadores com carteira assinada, a concessão florestal tem capacidade de ampliar em 20,19\% esse montante. No Estado do Amazonas, o acréscimo de carteiras assinadas poderia chegar a 78,45\% (Figura 3).

Figura 3 - Percentual da quantidade potencial de geração de empregos diretos e indiretos pela CF em relação ao número de trabalhadores com carteiras assinadas, por estado da Amazônia

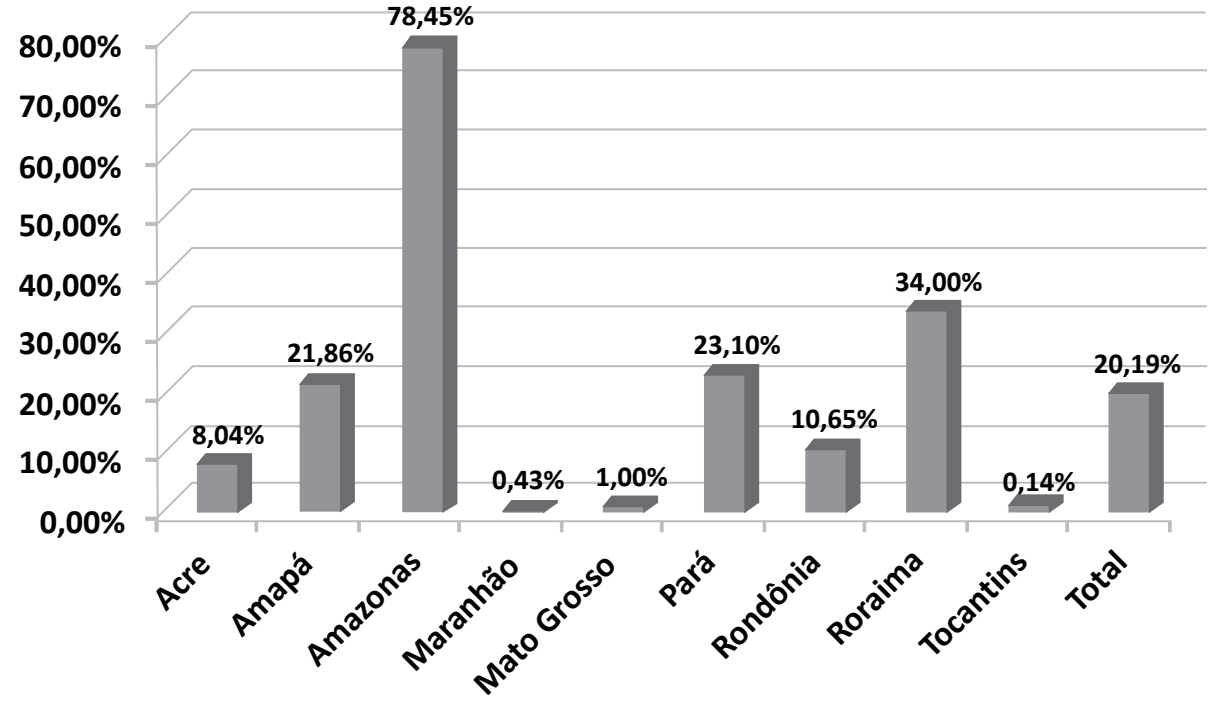

Fontes: Elaboração própria, a partir de IBGE ( 2013b) e IBGE (2014). 
Quanto à população desocupada, a quantidade de empregos factíveis de serem gerados poderia amenizar a situação em aproximadamente $65,96 \%$ na região (Figura 4). Conforme Ipea (2013b), a população desocupada é o conjunto de pessoas que procuraram mas não encontraram ocupação profissional remunerada na semana de referência da Pesquisa Nacional por Amostra de Domicílios (Pnad/IBGE).

Para o Estado de Rondônia, a avaliação foi, praticamente, a de obtenção do pleno emprego, ou seja, o alcance do ponto de equilíbrio entre a oferta e a demanda por mão de obra. No Estado do Amazonas, a previsão é de que o número de empregos a serem gerados pela concessão florestal seja 269,49\% maior que o número de desempregados, o que equivale dizer que poderia haver uma extrapolação do pleno emprego em 169,49\% (Figura 4).

Figura 4 - Percentual da quantidade potencial de geração de empregos diretos e indiretos pela CF em relação à população desocupada, por estado da Amazônia

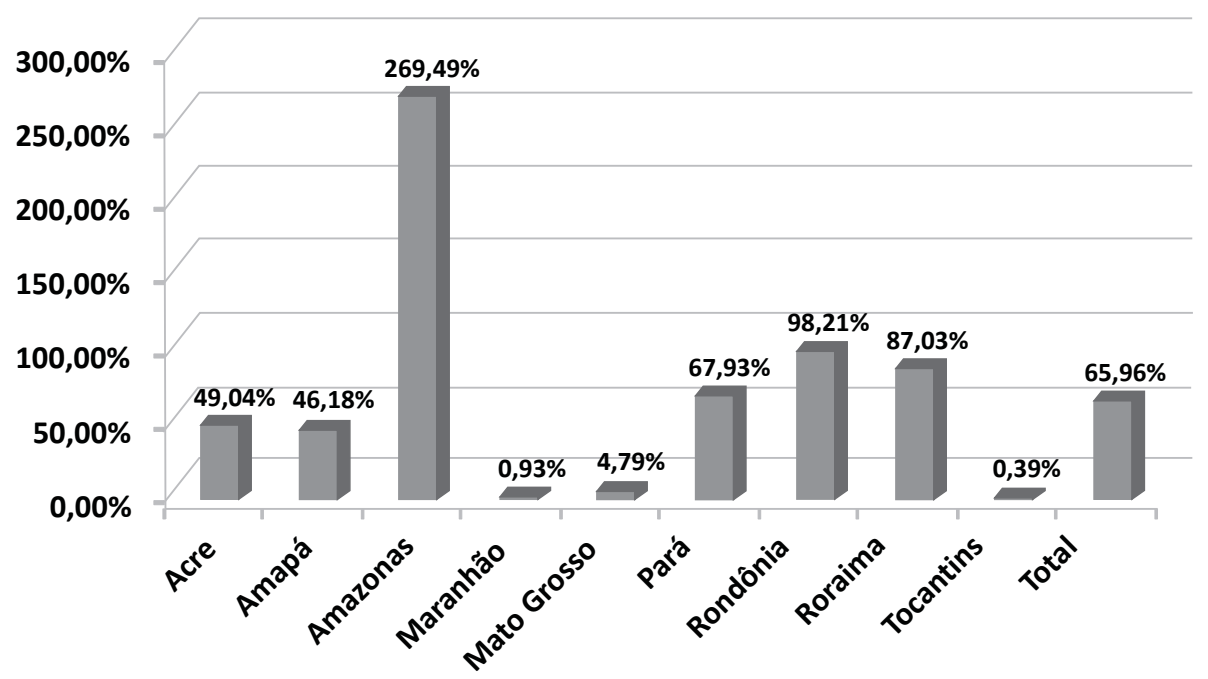

Fontes: Elaboração própria, a partir de Instituto de Pesquisa Econômica Aplicada (2013b).

Sabendo-se que tais empregos, em sua maioria, estão direcionados para as áreas rurais, onde se localizam as florestas passíveis de concessão, pode-se deduzir que esse instrumento seria apropriado não só para auxiliar na contenção do êxodo de pessoas para os centros urbanos, como também para promover o caminho inverso, atraindo para as áreas florestadas a massa desocupada desses centros ou de outras áreas rurais não contempladas com a concessão.

Obviamente, essa potencialidade está condicionada a fatores que extrapolam a governança das autoridades do setor florestal. Há a necessidade de que infraestruturas elementares (saúde, educação, transportes etc.) acompanhem as iniciativas florestais, ou seja, é preponderante a atuação conjunta de políticas 
públicas de outros setores, a fim de viabilizar economicamente o negócio e atrair interessados.

No que diz respeito à capacidade do mercado para absorver a oferta de madeira, proveniente da área calculada para concessão florestal, é oportuno salientar que SFB e Instituto de Pesquisa Ambiental da Amazônia (Ipam) (2011) estimaram que, até 1996, a média anual de produção de toras na Amazônia foi acima de 45 milhões de metros cúbicos. Tal volume, para ser sustentavelmente ofertado, a saber, mediante execução de planos de manejo florestal sustentável (PMFS), equivale, resguardadamente, a cerca de 52 milhões de hectares, considerando a produtividade legal de $0,86 \mathrm{~m}^{3} /$ ha/ano (52 milhões de hectares $\times 0,86 \mathrm{~m}^{3} /$ ha/ano = 45 milhões de metros cúbicos por ano). Cumpre ressaltar que não se pretende aqui vincular o mencionado volume de madeira a PMFS, porventura, existentes na época. O que se postula é que, para se chegar novamente e de maneira sustentável a esse patamar de produção, seriam necessários os citados 52 milhões de hectares de florestas manejadas anualmente.

Ainda de acordo com SFB e Ipam (2011), em 2009, a produção média de madeira em tora no Brasil decaiu para a ordem de 15 milhões de metros cúbicos. $O$ decréscimo de produção, de 1997 a 2009, foi atribuído, segundo SFB e Ipam (2011), às ações de fiscalização, à utilização de produtos substitutos e às crises econômicas internacionais.

Admitindo-se que a concessão florestal possa oferecer ao setor garantias de abastecimento contínuo de produto legal, é razoável acreditar em uma possível recuperação desse mercado e que ele seja, por efeito, potencialmente receptivo à oferta de madeira referente à área total estimada para a concessão de florestas públicas, ora ponderada em 45,3 milhões de hectares.

\section{Considerações finais}

De maneira geral, o estudo evidenciou a potencialidade da concessão de florestas públicas no que se refere à possibilidade de impulsionar o desenvolvimento socioeconômico da região amazônica, com ênfase para a geração de emprego e renda e consequente reflexo na redução da PE.

Os empregos a serem criados têm a particularidade de serem formais, verdes e sustentáveis. A maior presença do Estado no controle das áreas manejadas por meio de concessão prima pela redução de danos na exploração da floresta e pelo monitoramento da reposição de estoque dos produtos florestais extraídos. Além disso, auxilia no cumprimento das normas trabalhistas, conduzindo a atividade para um viés de sustentabilidade ambiental, social e econômica. 
Estimou-se a geração de 560.706 empregos (diretos e indiretos), representando

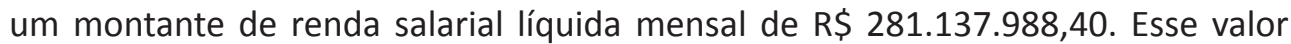
equivale, aproximadamente, a 36,3\% do VR associado à PE na região amazônica. $O$ VR foi definido neste estudo como o valor total mensal de cestas básicas necessárias para que nenhuma pessoa viva nessa condição de pobreza na Amazônia.

É patente que não há como prever qual percentual da renda salarial estimada teria destinação direta àqueles que vivem em PE. Mas, se é sensato admitir que boa parte do desemprego agrave a situação da miséria, então, é esperado que também uma parcela considerável dessa renda venha atuar na solução do problema. Conforme Moreira (2012), a geração de empregos, somada ao crescimento econômico e à estabilização, faz surtir o efeito esperado de decréscimo da desigualdade, que, por sua vez, diminui a pobreza de uma nação. Então, a criação de emprego e renda, por meio da concepção de desenvolvimento sustentável que é a concessão florestal, associada a programas de qualificação profissional, aparece como forma viável e estratégica de redução dos problemas de PE encontrados na Região Amazônica.

Outro efeito almejado é o de uma melhor distribuição geográfica da população, auxiliando (de maneira racional e com respeito aos espaços de preservação ambiental e cultural) na resposta à baixa densidade demográfica que ocorre nas áreas rurais da Amazônia e na solução dos crônicos problemas de logística que insistem em desafiar o desenvolvimento da região.

O impacto socioeconômico que a concessão florestal projeta para a população rural da Amazônia, demonstrado neste estudo, intima a adoção de uma política florestal dinâmica e sistêmica, entre a União e os entes federativos, na busca de soluções sustentáveis para o progresso econômico e o bem-estar regional.

Assim, o que se deve ter em mente é o aproveitamento da potencialidade das florestas para melhorar a qualidade de vida em regiões onde seus habitantes convivem com o paradoxo de subsistir com baixos indicadores socioeconômicos em meio a uma exuberante riqueza de recursos naturais renováveis.

\section{Referências bibliográficas}

Albuquerque, G. P. Análise de conflitos do sistema de concessões florestais no Brasil. 2009, 254 f. Dissertação (Mestrado em Desenvolvimento Sustentável) - Centro de Desenvolvimento Sustentável - Universidade de Brasília, Brasília, 2009.

AlLEN, C.; CLOUTH, S. A guidebook to the green economy - issue 1: green economy, green growth, and low-carbon development - history, definitions and a guide to recent publications. New York: Undesa, 2012. 64 p. 
ARIMA, E.; BARRETO, P. Rentabilidade da produção de madeira em terras públicas e privadas na região de cinco florestas nacionais da Amazônia. Brasília: Ministério do Meio Ambiente, 2002. 49p.

BomfIM, S. L. Índice de clima econômico para concessões florestais. 2014. $152 \mathrm{f}$. Tese (Doutorado em Ciência Florestais) - Departamento de Engenharia Florestal, Universidade de Brasília, Brasília, 2014.

BRASIL. Lei 11.284, de 02 de março de 2006. Dispõe sobre a gestão de florestas públicas para a produção sustentável; institui, na estrutura do Ministério do Meio Ambiente, o Serviço Florestal Brasileiro - SFB; cria o Fundo Nacional de Desenvolvimento Florestal - FNDF; altera as Leis $n^{\text {os }} 10.683$, de 28 de maio de 2003, 5.868, de 12 de dezembro de 1972, 9.605, de 12 de fevereiro de 1998, 4.771, de 15 de setembro de 1965, 6.938, de 31 de agosto de 1981, e 6.015, de 31 de dezembro de 1973; e dá outras providências. Normas Florestais Federais para a Amazônia. Brasília, Ibama, 2007. p. 59-99

BRASIL. Lei 12.651, de 25 de maio de 2012. Dispõe sobre a proteção da vegetação nativa; altera as Leis $n^{\text {os }} 6.938$, de 31 de agosto de 1981, 9.393, de 19 de dezembro de 1996, e 11.428, de 22 de dezembro de 2006; revoga as Leis $n^{\text {os }} 4.771$, de 15 de setembro de 1965, e 7.754, de 14 de abril de 1989, e a Medida Provisória n².16667, de 24 de agosto de 2001 e dá outras providências. Disponível em: < http://www. planalto.gov.br/ccivil_03/_ato2011-2014/2012/lei/I12651.htm>. Acesso em: 29 de abr. de 2016.

CAMPOS, C. H. O processo de implementação das concessões florestais no Brasil: de março de 2006 a dezembro de 2010. 2011. 127 f. Monografia (Curso de Especialista em Gestão Pública Ambiental) - Centro de Desenvolvimento Sustentável, Universidade de Brasília, Brasília, 2011.

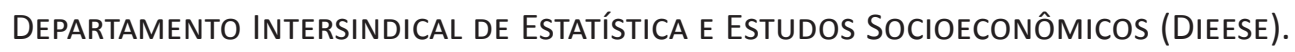
Disponível em <http://www.jboss.dieese.org.br/cesta/cidade>. Acesso em set. 2014a.

DEPARTAMENTO INTERSINDICAL DE ESTATística E ESTUdos SOCIOECONÔMICOS (DIEESE). Disponível em: <http://www.dieese.org.br/analisecestabasica/salarioMinimo. html >. Acesso em: set. 2014b.

EsPeCial ReVISTA VejA. O homem da Amazônia: o fator humano. São Paulo: Editora Abril, set. 2009. Especial Amazônia.

GóıS, S. L.L. Gestão de florestas públicas na amazônia legal: consensos de uma disputa. 2011. 225 f. Tese (Doutorado em Desenvolvimento Sustentável) - Centro de Desenvolvimento Sustentável, Universidade de Brasília. Brasília, 2011.

Heidemann, F. G.; SAlm, J. F. (Orgs.). Políticas públicas e desenvolvimento: bases epistemológicas e modelos de análise. 2. ed. Brasília: Editora Universidade de Brasília, 2010. 338 p.

INSTITUTO BRAsileiro de Geografia e EStatística (IBGE). Valor da produção na extração vegetal, por tipo de produto extrativo. Disponível em: <http://www.ibge. gov.br/home>. Acesso em: 19 nov. 2013a. 
Instituto BRAsileiro de Geografia e Estatística (IBGE). Mercado e força de trabalho - mercado de trabalho - carteira de trabalho assinada - empregados total e por sexo - 2011. Disponível em: <http://seriesestatisticas.ibge.gov.br/series. aspx?no $=7 \& o p=0 \& v$ codigo=PD352\&t=carteira-trabalho-assinada-empregados total-sexo>. Acesso em: 03 dez. 2013b.

instituto Brasileiro de Geografia e Estatística (IBGE). Mercado e força de trabalho - mercado de trabalho - população economicamente ativa - sexo - 2011. Disponível em: <http://seriesestatisticas.ibge.gov.br/series.aspx?no=7\&op=0\&v codigo= PD295\& $t=$ sexo $>$. Acesso em: 14 jan. 2014.

INSTITUTO INTERNACIONAL DE EDUCAÇÃO DO BRASIL (IEB). Regularização fundiária e manejo florestal comunitário na Amazônia: sistematização de uma experiência inovadora em Gurupá-PA. Brasília : IEB, 2011. 70 p.

INSTITUTO DE PESQUISA ECONÔMICA APLICADA (IPEA). Social - mercado de trabalho população economicamente ativa (PEA). Disponível em: <http://www.ipeadata.gov. br/> Acesso em 21 nov. 2013a.

Instituto de Pesquisa EConômica Aplicada (IPEA). Social - mercado de trabalho - população desocupada - 2011. Disponível em: <http://www.ipeadata.gov.br/> Acesso em 21 nov. 2013b.

INSTITUTO DE PESQUISA ECONÔMICA APLICADA (IPEA). Social - renda - número de indivíduos extremamente pobres - linha de pobreza baseada em necessidades calóricas - 2011. Disponível em: <http://www.ipeadata.gov.br/> Acesso em: 18 ago. 2014.

Instituto de PESQUisa ECONÔMicA Aplicada (IPEA). Concessões florestais fundamentos e perspectivas. Disponível em: <http://www.ipea.gov.br/ agencia/ images/stories/PDFs/091204sembiodmarcelo.pdf> Acesso em: 29 abr. 2016.

KAHN, J. R. A contribuição potencial da avaliação econômica para o processo de tomada de decisão. In: RivaS, A.; FreITAS, C. E.; MourÃo, R. R. (Org.). Valoração e instrumentos econômicos aplicados ao meio ambiente: alternativas para proteger a Amazônia. Manaus: DP Indústria de Etiquetas, 2008. p. 29-37.

Kramer, R. A.; Holmes, T. P.; HAefele, M. Contingent valuation of forest ecosystem protection. In: SILLS, ERIN O.; ABT, KAREN L. (Org). Forests in a market economy. Forestry sciences. v. 72. ed. Dordrecht: Kluwer Academic Publishers, 2003. p. 303-320.

MOREIRA, A. R. F. Influência das políticas públicas e dos programas sociais de combate à pobreza no desempenho econômico e social de municípios selecionados do Estado de Mato Grosso do Sul no período de 200-2010. 2012, 162 f. Tese (Doutorado em Economia) - Faculdade de Ciências Econômicas, Universidade Federal do Rio Grande do Sul, Porto Alegre, 2012.

OLIVEIRA, R. M. F. Concessão florestal: exploração sustentável de florestas públicas por particular. São Paulo: JHMizuno, 2013. 373p.

PEREIRA, D. et al. Fatos florestais da Amazônia 2010. Belém: Imazon, 2010. 122p.

RochA, J. D. S.; SILVA, J. A. As funções de Estado na área florestal: suas inter-relações com a Constituição Federal e com o programa nacional de florestas. Revista Floresta, Curitiba, v. 39, n. 2, p. 253-271, 2009. 
Reydon, B. P. O desmatamento da floresta amazônica: causas e soluções. Política Ambiental / Conservação Internacional, Belo Horizonte, n. 8, p. 143-155, 2011.

SABOGAL, C. et al. Manejo florestal empresarial na Amazônia brasileira: restrições e oportunidades. Belém: Cifor, 2006. 72p.

SAUER, S.; LeITE, S. P. Expansão agrícola, preços e apropriação da terra por estrangeiros no Brasil. Revista de Economia e Sociologia Rural, Brasília, v. 50, n. 3, p. 503-524, 2012.

SERVIÇO FloRestal BRASILEIRo (SFB). Concessões florestais - pré-editais lançados. Disponível em: <http://www.sfb.gov.br/pre-editais-lancados>. Acesso em: 01 nov. 2012.

Serviço Florestal Brasileiro (SFB). Plano anual de outorga florestal 2014. Brasília: SFB, 2013a. 116p.

Serviço Florestal Brasileiro (SFB). Cadastro nacional de florestas públicas: atualização 2010. Disponível em: <http://www.florestal.gov.br/informacoesflorestais/cadastro-nacional-de-florestas-publica>. Acesso em: 01 fev. 2013b.

SERVIço Florestal BRAsileiro (SFB). Concessões florestais - editais abertos. Disponível em: < http://www.florestal.gov.br/editais-abertos/>. Acesso em: 30 nov. 2013c.

Serviço Florestal BRASileiro (SFB). Concessão florestal - um novo paradigma de uso das florestas. Disponível em: <http://www.florestal.gov.br/concessoesflorestais/o-que-e-concessao-florestal/concessao-florestal-um-novo-paradigmade-uso-das-florestas. Acesso em: 29 de abr. $2016 a$.

SERVIÇO FloRESTAL BRASILEIRO (SFB). Instrumento de gestão - gestão de florestas públicas - relatório de 2015. Disponível em: <http://www.florestal.gov.br/ publicacoes/ instrumento-de-gestao>. Acesso em: 29 de abr. 2016b.

Serviço Florestal Brasileiro (SFB); instituto do homem e Meio Ambiente da AMAZÔNIA (IMAZON). Atividade madeireira na Amazônia brasileira: produção, receita e mercados. Belém: Imazon, 2010. 20p.

SERVIço Florestal BRASILEIRo (SFB). Plano anual de outorga florestal 2011. Brasília: SFB, 2010. 122p.

Serviço Florestal BRASileiro (SFB); Instituto de Pesquisa Ambiental da AMAZÔnia (IPAM). Florestas nativas de produção brasileiras. Brasília: SFB, 2011. 24p.

SIMON, M. F.; GARAGORRY, F. L. The expansion of agriculture in the Brazilian Amazon. Environmental Conservation, Cambridge v. 32, n. 3, p. 203-212, 2005.

WUNDER, S. et al. (Org). Pagamentos por serviços ambientais: perspectivas para a Amazônia Legal. Série Estudos. 10. ed. Brasília: MMA, 2008. 134 p. 
Sergio Luiz do Bomfim

Possui doutorado em Ciências Florestais pela Universidade de Brasília (UnB). Atua como Analista Ambiental e coordenador de monitoramento e auditoria florestal do Serviço Florestal Brasileiro (SFB).

Contato: sergiunbomfim@gmail.com

Alexandre Louis de Almeida D’Avignon

Possui doutorado em Planejamento Energético pela Universidade Federal do Rio de Janeiro (UFRJ). Atua como Analista Ambiental do Ministério do Meio Ambiente e da Amazônia Legal.

Contato: alexandre.davignon@mma.gov.br

Álvaro Nogueira de Souza

Possui doutorado em Engenharia Florestal pela Universidade Federal de Lavras (UFLA). Atua como Professor Adjunto da Universidade de Brasília (UnB).

Contato: ansouza@unb.br

Paulo José Prudente de Fontes

Possui doutorado em Ciências Florestais pela Universidade de Brasília (UnB). Atua como Analista Ambiental do Ministério do Meio Ambiente.

Contato: paulo.fontes@florestal.gov.br

Maísa Santos Joaquim

Possui doutorado em Ciências Florestais pela Universidade de Brasília (UnB). Atua como docente de nível superior na Universidade de Brasília (UnB).

Contato: maisaunb@gmail.com 